\title{
O RACISMO ANTINEGRO, A PSICANÁLISE E A SUBJETIVIDADE DA NOSSA ÉPOCA NO BRASIL
}

KON, Noemi: SILVA, Maria Lucia da; e ABDUL, Cristiane (orgs.). O racismo e o negro no Brasil: questões para a psicanálise. São Paulo: Perspectiva, 2017. 304p.

66 Já que é preciso, de qualquer modo, não lhes pintar unicamente um futuro cor-de-rosa, saibam que o que vem aumentando, o que ainda não viu suas últimas consequências e que, por sua vez, se enraíza no corpo, na fraternidade do corpo, é o racismo. Vocês ainda não ouviram a última palavra a respeito dele". ${ }^{1}$ Com essas palavras que hoje assumem ares proféticos, o psicanalista francês Jacques Lacan (1901-1981) terminava um dos seus seminários em 1972.

Mas, mesmo que o "lacanismo" seja a orientação teórica psicanalítica predominante entre nós, e em 1983 tenhamos a publicação de uma obra

1 Jacques Lacan, O seminário: livro 19: ... ou pior 1972 (2007), Rio de Janeiro: Zahar, 2012, p. 227. ainda pouco lida da lacaniana negra Neusa Santos Souza sobre a questão, apenas em 2017 vemos o lançamento de um livro coletivo que tematiza de forma ampla e essencial o fenômeno do racismo antinegro no país. ${ }^{2}$ Organizado por três psicanalistas, a coletânea aqui resenhada reúne artigos

2 Me referi ao livro de Neusa Santos Souza, Tornar-se negro, Rio de Janeiro: Graal, 1983. Também não posso deixar de fazer menção, entre outros, aos trabalhos pioneiros sobre as relações raciais de Virgínia Bicudo, mulher negra considerada primeira psicanalista do Brasil; aos textos de Lélia Gonzalez (1935-1994) que mobilizam a psicanálise para pensar o racismo e o sexismo no país; ao livro organizado por Iray Carone e Maria Aparecida Silva Bento (orgs.), Psicologia social do racismo, Petrópolis: Vozes, 2002, e à tese de doutorado de Isildinha Baptista Nogueira, "Significações do corpo negro”, Tese (Doutorado em Psicologia), Universidade de São Paulo, 1998. 
fruto de um evento realizado em 2012 pelo Departamento de Psicanálise do Instituto Sedes Sapientiae e por psicanalistas militantes do movimento negro de São Paulo.

O antropólogo Kabengele Munanga abre o volume com o texto "As ambiguidades do racismo à brasileira”, abordando o tema enquanto fenômeno presente em diversas sociedades contemporâneas, mesmo que a racionalidade científica demonstre o absurdo de crenças e afirmações sustentadas em qualquer ideia de superioridade ou inferioridade raciais de grupos humanos. No Brasil, diferentemente de outros países, temos uma série de ambiguidades no que diz respeito a reconhecer e refletir essa questão: para muitos o país sequer é racista, sendo a questão econômica ou de classe social fator determinante para os processos discriminatórios; e, para quem afirma existir o racismo, sempre o outro é quem o comete.

$\mathrm{O}$ autor mostra como argumentos ao arrepio das evidências históricas e exceções factuais mitificadas são articulados para desmobilizar as lutas das pessoas que sofrem o racismo e como o silêncio é uma característica que o torna um "crime perfeito" (p. 40). Uma dinâmica de funcionamento que torna superior determinados discursos da pessoa branca especialista em pessoas negras, tampa os ouvidos para a escuta destas e obstaculiza a tomada de consciência da situação pela sociedade como um todo.

Em "Dessemelhanças e preconceitos", Heidi Tabacof conta como o recurso ao sociodrama enquanto metodologia de trabalho no evento pôde tocar nessa dor condenada ao silêncio que, porém, faz-se presença constante no país. A violência escondida pelo racismo brasileiro pôde ser exposta e, com isso, perdeu "o habitual disfarce que a mantém latente e muda” (p. 46), fazendo inclusive surgir a discussão sobre a diferença entre o preconceito contra pessoas judias e negras, o que evidencia conflitos latentes até então não percebidos. Trata-se daquilo que não é dito e torna ainda mais difícil que a dor e a glória desses grupos discriminados e violentados sejam narradas e transmitidas para que se possa processar as experiências traumáticas e assim ultrapassá-las.

O capítulo "A violência nossa de cada dia: o racismo à brasileira”, 
de Maria Carvalho Vennuchi, se propõe a pensar o racismo antinegro como sintoma coletivo herdado da escravatura e atualizado pela violência que constitui a sociabilidade brasileira, interpretado a partir dos textos sociais de Freud. Ao passar pelas discussões freudianas clássicas acerca do mito fundador do contrato social (a morte do pai da horda primitiva), a agressividade humana e a tarefa da civilização em regular os laços sociais, a autora reflete como a violência social não é um dado natural. Construção a serviço das necessidades de autoconservação dos grupos que, ao se formarem coletivamente, buscam fortalecer laços internos e elegem como o estranho ao grupo que será alvo da agressividade, o racismo seria justamente um fenômeno primitivo de estranhamento e angústia intrínseco à formação da identidade, refratário aos argumentos racionais. Neste caso, se escolhe odiar a "pequena diferença" de certo grupo igualmente humano tido como de algum modo diverso.

Porém, o momento mais interessante do seu texto é quando a autora recorre ao prefácio do livro de Neusa Santos Souza, Tornar-se Negro, para pensar os efeitos do racismo na constituição da subjetividade negra, já que a violência introjetada acarreta uma negação de si, do valor mais elementar atribuído a si (ao seu próprio corpo negro). Uma consequência possível é o "desejo que deságua no desejo da própria extinção” (p. 67), que com a denegação do racismo operada pelo discurso corrente - e pela própria escuta psicanalítica que desconsidera o fenômeno - faz com que pessoas negras coloquem em dúvida a realidade da violência de gestos e falas cotidianas que reproduzem a discriminação e figurem como paranoicas dotadas de um discurso "vitimista".

Em "Racismo no Brasil: questões para psicanalistas brasileiros”, a psicóloga e psicanalista Maria Lúcia da Silva compartilha sua experiência de mulher negra que vivenciou uma situação de racismo numa aula de psicanálise do Instituto SEDES e suas inquietações acerca de uma demanda reprimida para as pessoas negras que acreditam no potencial transformador da psicanálise. Ou seja, o racismo não pode ser tratado como uma "queixa” individual, pois constitui responsabilidade coletiva da qual as pessoas brancas (inclusive as praticantes 
da psicanálise) não podem deixar de se implicar.

Outro eixo importante do seu capítulo é ressaltar que a maior vitória do racismo está na sua dimensão psicológica, naquilo que marca a constituição subjetiva das pessoas negras nos processos de identificação, fabricação de identidades e produção de sintoma, essa solução encontrada pelo psiquismo para manter fora da consciência conteúdos ligados a uma dor produzida por vivências desprazerosas. Ademais, toca num ponto ainda pouco discutido pela literatura: as influências que as representações negativas sobre o ser negro/a/e exercem na psique da criança negra no Brasil. Mais do que afirmar que o narcisismo é fruto da relação com os pais, é preciso pensar que os ideais de branquitude numa sociedade racista podem impactar mesmo essas figuras que cumprem a função social de maternagem e paternagem.

No texto "Raça, cor e linguagem”, a historiadora e antropóloga Lilia Moritz Schwarcz faz uma espécie de cartografia de algumas das principais teorias raciais que surgem desde o século XVIII e influenciam ou se tornam explicações acerca das diferenças humanas ao longo do XIX. Alguns desses modelos de determinismo geográfico e social foram empregados para pensar as idiossincrasias dessa que foi a última nação a abolir a escravidão no Ocidente. Tido como verdadeiro "laboratório vivo de raça”, internamente o país "oscilava na sua representação: ora éramos definitivamente degenerados, ora divinamente mestiços” (p.101-102), o que ajuda a entender as ambiguidades presentes nas pesquisas sobre o racismo: ao mesmo tempo que reconhecem a existência do fenômeno, as pessoas sempre o situam no outro e não em si, como se cada brasileiro fosse uma "ilha de democracia racial cercada de racismo por todos os lados” (p. 116).

Ao discutir o racismo como uma forma de linguagem social viva presente em provérbios (frases e ditos populares) entranhados nos nossos costumes, a autora possibilita interrogar sobre como o racismo atravessa as formações do inconsciente no Brasil. Expressões tais quais "à noite, todos os gatos são pardos” ou "eles que são brancos que se entendam” denotam a força das cores na constituição do vocabulário interno desta 
comunidade mestiça imaginada na qual se tem "preconceito de ter preconceito" (como dizia Florestan Fernandes). Porém, as desigualdades raciais vicejam em todas as estatísticas, ainda que a identificação racial varie contextualmente. Assim, os termos e nomes mudam de feição e formato conforme o cálculo racial subjetivo de cada um, mas ser nomeado ou dizer-se “negra/o/e" jamais pode ser considerado neutro e o racismo, enquanto nossa linguagem interna, acontece de maneira "violenta, nos pequenos e grandes atos diários” (p. 118).

Num texto curto mas preciso, “Cor e inconsciente”, a psicóloga e psicanalista Isildinha Baptista Nogueira reflete, à luz da teoria lacaniana, como o significante "cor negra” e a realidade sociocultural do racismo articulam um arranjo semântico, político, econômico e histórico que produz um apartheid psíquico, moldando inconscientemente a estrutura psíquica da pessoa negra, mesmo que esta tenha plena consciência do racismo. Afinal, desde Freud sabemos o quanto escapa à nossa vontade - ao domínio da nossa razão narcísica - lançar mão de um aparato lógico-racional para lidar com certos fenômenos inscritos na psique durante o processo da nossa constituição subjetiva.

Acontece que, para a pessoa negra, a imagem de si "forjada na relação com outro - e no ideal de brancura - não só não guarda nenhuma semelhança com o real de seu corpo próprio mas é por este negada” (p. 124), o que cria angústia, confusão entre o real e o imaginário, introjeção de uma agressividade que leva à autorrejeição e, no limite, uma despersonalização em que o sujeito torna-se autômato, alienado ao desejo do outro. Como lidar com essas questões sendo uma pessoa negra na função de psicanalista? "Permanece o medo de romper a tênue linha da sensibilidade humana e me expor como personagem de meu drama pessoal, perdendo de vista a sensibilidade do analista que trabalha com sintomas que falam do paciente, mas também dele, que escuta” (p. 125), ressalta a autora. Mas ainda nos falta estender esse tipo de pergunta às pessoas brancas que atendem pessoas brancas em relação à branquitude que as aproxima.

Fúlvia Rosemberg, em “Psicanálise e relações raciais”, 
na condição de pesquisadora da educação, interroga o tratamento dado à infância no âmbito das relações raciais, tendo em vista uma perspectiva que leva em consideração as dimensões materiais e simbólicas do racismo. Desse modo, propõe pensar, simultaneamente, como se articulam a condição socioeconômica e de pertença racial na sua interface com outros marcadores (classe, gênero e idade) para a produção de um racismo complexo, que está presente nas relações familiares, escolares e, estruturalmente, nas instituições de um modo geral. Ao questionar em que momento uma pessoa é ou se torna racista, partindo do pressuposto de que ideologia racial de superioridade branca é forjada no universo adultocêntrico, a creche, a pré-escola, a pequena infância e o papel que as crianças possuem na construção de sociedades racistas tornam-se focos de preocupação até então pouco investigados.

Já em "A dominação racista: passado presente”, José Moura Gonçalves Filho parte do capítulo anterior para pensar como o racismo contra pessoas negras não se manifesta apenas no plano das relações pessoais, mas cristaliza-se nas diversas instituições e provoca efeitos de segregação e rebaixamento que se automatizam em procedimentos e instâncias muitas vezes invisíveis, sustentadas por práticas racistas, conscientes ou não. Ora, o racismo opera processos de dominação de um grupo sobre o outro e, como tal, não se perfaz sem desejo e fantasia: o desejo de dominar se constitui em grupo e tem sempre um objeto de satisfação fantasmática de quem domina, que numa estrutura racista não domina só, pois precisa se reunir em cumplicidade com aqueles que considera parceiros.

Sintomático é o autor falar do Instituto AMMA Psique e Negritude, espaço em que as iniciativas de resistência, questionamento e transformação em relação ao racismo são articuladas por uma rede de profissionais negras/os/es. Com efeito, tal grupo se une de modo não servil e faz laço social no presente na luta contra a dominação racista, esse vínculo com o passado escravista que, como disse o historiador Luiz Felipe Alencastro em relação ao escravismo, não se trata apenas de uma herança colonial, mas uma formação de compromisso 
para o futuro que projeta as relações de escravidão/servidão racial na contemporaneidade. ${ }^{3}$

Em "Racismo, uma leitura", Moisés Rodrigues Junior analisa o processo histórico de formação das identidades e os impactos da violência racista nas relações de dominação e opressão. As discussões e perspectivas sobre a escravidão, o surgimento da noção de raça e o fenômeno do racismo como consolidação de uma visão da pessoa negra como o “outro", no que tem de ideológico e na sua relação com o expansionismo religioso judaico-cristão, forram a discussão mais psicanalítica sobre “o estranho”, os processos de identificação - mecanismo privilegiado da constituição do $\mathrm{Eu}$ - e as relações de alienação e assimetria.

Umareflexãoquepermiteponderar o quanto a pessoa negra, desvalorizada em sua singularidade, passa por experiências de interdição, sofrimento e espoliação da sua subjetividade. Mas será que toda pessoa negra vive esse

3 Luiz Felipe de Alencastro, "Vida privada e ordem privada no Império” in L. F. de Alencastro (org.) e Fernando Novais (coord.), História da vida privada no Brasil (São Paulo: Companhia das Letras, 1997), v. 2, pp. 16-17. processo da mesma forma? A psicanálise precisa não tornar a experiência do sujeito atomizada, presa a uma perspectiva individualizante, visto que o próprio Freud já questionava a diferença de natureza entre indivíduo e sociedade (ou possibilidade de operar essa separação); mas também precisa se perguntar o modo como cada pessoa negra vivencia singularmente esse sofrimento.

Em "Buscando baobás na aridez do asfalto: instaurando origens”, a psicanalista Miriam Chnaiderman articula clínica psicanalítica, pensamento feminista negro, cinema e literatura para explorar as possibilidades de construção de narrativas que visem dar conta de uma origem negada. Uma das dimensões mais fecundas do texto é cogitar o quanto o silenciamento da história de um povo e de sua herança cultural não implica apenas em recalque que leva a conflitos sociopsíquicos, mas a uma negação da dignidade humana no tempo presente, daí a necessidade de se inventar genealogias (no plural), já que no mundo branco a subjetividade da pessoa negra passa por tortuosos caminhos para se constituir, contexto no qual é levada a ficar 
enclausurada ao seu corpo marcado pela violência do ideal de brancura.

Com o texto "Quem tem medo da palavra negro”, o escritor e professor Luiz Silva, conhecido como CUTI, contribui para o debate com um resgate histórico dos usos negativos do termo negro e de como ele foi ressignificado pelo movimento negro; e denuncia o racismo como patologia social de um grupo hegemônico que inverte o lugar onde está a doença psíquica e ao mesmo tempo opera preventivamente contra aquilo que o assusta enquanto possibilidade de reação. Assim, fica evidente que os impasses que as questões da identidade pessoal assumem no Brasil não serão resolvidas pela negação do significante negro - e utilização do termo "afro” -, pois esse procedimento, na verdade, não ajuda no combate ao racismo, esconde mais ainda o medo identitariamente branco.

Em "A questão do racismo em um grupo de mediação com fotografias”, a psicóloga Cristiane Curi Abud e a fotógrafa Luiza Sigulem abordam o racismo por meio da fotografia, numa experiência psicoterápica com base psicanalítica a partir de um "enquadre grupal”. O relato contribui para que um dos pontos chaves da teoria lacaniana da constituição do Eu possa ser explorado numa reflexão sobre o racismo antinegro e os processos de representação da diferença. ${ }^{4}$ Nesse dispositivo grupal que assume a função de reeditar o momento de unificação da imagem do corpo próprio e diferenciação em relação ao outro, as pessoas pacientes, e não a analista, parecem trazer os melhores questionamentos em relação a um certo imaginário social que transforma o estranho em objeto a ser excluído, e converte a diferença em desigualdade.

Com o capítulo "O racismo nosso de cada dia e a incidência da recusa no laço social”, a psicanalista Tânia Corghi Veríssimo possibilita aprofundar a reflexão sobre o quanto o silenciamento a respeito do racismo que se pratica tanto na sociedade, quanto na clínica, implica na incidência da recusa do laço social a partir do qual a pessoa negra se vê impossibilitada pensar-se. Processo transgeracional, a abolição simbólica pela qual passa o corpo negro e a

4 Presente em "O estádio do espelho como formador da função do eu” in Jacques Lacan, Escritos (Rio de Janeiro: Jorge Zahar, 1988), pp. 96-103. 
subjetividade negra, submetidos a um ideal de brancura fetiche, evidencia-se como uma questão que ainda não foi minimamente elaborada, potencializando os impasses trazidos pelos elementos “não ditos" inerentes a uma linguagem nacional marcada pelo escravismo. O texto ajuda a interrogar essa complicada relação entre história social e estrutura de linguagem, que grande parte das/dos/des psicanalistas "recusa" discutir.

Pedro Mascarenhas, psicodramatista e psicanalista, traz o relato de um sociodrama ocorrido no evento que deu origem ao livro. Em "Estranho jogo amargo: desconstruindo a vitimização nos jogos racistas” ele pontua a importância de não se ignorar o mal-estar causado pelo racismo e como o sociodrama torna-se um instrumento aliado nesse processo. Afinal, "psicanalista também tem preconceito” (p. 275) e o próprio instituto promotor do evento, composto e dirigido por maioria branca, pode contribuir para que o racismo antinegro e o sofrimento psíquico dele decorrente sejam colocados em questão fora dos rótulos de suposto vitimismo no qual parte das instituições psicanalíticas reiteradamente tenta enquadrar o protesto e a fala negro/a/es.

Por fim, Maria Célia Malaquias, em "Relações raciais no palco da vida: considerações sociátricas”, mobiliza as contribuições da psicanalista Neusa Santos Souza sobre o sofrimento psíquico para quem “a escravidão acabou, mas a luta continua” (p. 284). As reflexões que ela faz ao abordar o palco do drama e o palco da vida oportunizam pensar a necessidade de se produzir novas considerações psicanalíticas sobre tema tão central na constituição da sociedade brasileira, e não sem a ajuda de outros saberes.

É fato que não existe no livro uma discussão que articule racismo antinegro e colonialismo no que tange aos pressupostos epistemológicos eurocêntricos da própria psicanálise. Atualmente, muitas são as discussões feitas quanto aos limites de um saber inicialmente constituído por Freud a partir da experiência de sofrimento das pessoas brancas neuróticas, culturalmente situadas na Europa. ${ }^{5}$

5 O trabalho pioneiro de Frantz Fanon (Pele negra, máscaras brancas, Salvador: EDUFBA, 2008) é incontornável para nos ajudar nesse sentido. Outra referência importante mais recente e que dialoga 
Na apresentação do livro, Noemi Kon conclama pela necessidade de se avançar na construção de "uma psicanálise brasileira”, coisa que parece difícil de fazer sem lidar com questões próprias da experiência subjetiva das/dos/des brasileires e sem o diálogo com outras perspectivas epistemológicas (indígenas, africanas, latinoamericanas), tendo em vista a miscigenação que marca a própria história local.

Contudo, se, como disse Lacan retornando a Freud, “deve renunciar à prática da psicanálise todo analista que não conseguir alcançar em seu horizonte a subjetividade de sua época”, ${ }^{6}$ o livro, desde a sua publicação, se estabelece como um clássico. Característica que se expressa, principalmente, pela publicação dar a conhecer um campo imenso de problemas e questões que não podem ser silenciados, diante dos quais não se pode recuar, e que ajuda a abordar de diversas maneiras.

com Fanon é o livro de Grada Kilomba Memórias da plantação: episódios de racismo cotidiano, Rio de Janeiro: Editora Cobogó, 2019.

6 Jacques Lacan, "Função e campo da fala e da linguagem” in Lacan, Escritos, p. 321.
Quanto aos temas aqui discutidos, parte da resistência a eles pelas pessoas que praticam a psicanálise está em admitir que é preciso recorrer a uma interlocução profunda com o campo das Ciências Humanas, evitando uma práxis que leva a uma endogenia teórica dogmática e desatrelada da própria experiência clínica brasileira, algo que o trabalho que resultou neste livro buscou fazer. O racismo e o colonialismo são fenômenos complexos, incidem de maneira brutal sobre os negros, mas Frantz Fanon, em 1952, já denunciava o fato de constituírem a subjetividade de toda e qualquer pessoa (branca ou negra), não sendo apenas "um problema de negro". ${ }^{7}$ O filósofo Achille Mbembe também tem demonstrado que a experiência das plantations e o colonialismo foram centrais na constituição da modernidade e como, na era do neoliberalismo, o "devir negro" tornou-se uma tendência global, convertendo grupos cada vez mais amplos a uma condição (objetiva e subjetiva) subalternizada.

Ao final da leitura do livro, percebemos que o fenômeno do racismo

7 Frantz Fanon, Pele negra, máscaras brancas. 
e a experiência negra podem não ter surgido com a psicanálise, nem ter sido tematizados por Freud ou pelas sucessivas escolas e perspectivas que se propuseram a atualizar essa práxis discursiva, mas trazem perguntas que não podem ser de modo algum menosprezadas pelas pessoas que praticam a psicanálise no Brasil. O título da obra se faz então inteiramente justificado: o racismo e o negro no Brasil - questões para a psicanálise.

Jeferson de Jesus Nicácio (D)

Campo Psicanalítico de Salvador 